\title{
Detailed Analysis of Insulin Absorption Variability and the Tissue Response to Continuous Subcutaneous Insulin Infusion Catheter Implantation in Swine
}

\author{
Jasmin R. Hauzenberger, MSc, ${ }^{1,2}$ Brian R. Hipszer, PhD, Channy Loeum, Peter A. McCue, MD, \\ Mark DeStefano, Marc C. Torjman, PhD, Mahmut T. Kaner, MD, Alek R. Dinesen, MS, \\ Inna Chervoneva, $\mathrm{PhD}^{5}$ Thomas R. Pieber, $\mathrm{MD}^{2}$ and Jeffrey I Joseph, $\mathrm{DO}^{1}$
}

\begin{abstract}
Background: Worldwide, $\sim 1$ million people manage their type 1 diabetes with an insulin pump and a continuous subcutaneous insulin infusion (CSII) catheter. Patients routinely insert a new catheter every 2-3 days due to increasing variability of insulin absorption over time. Catheter insertion and maintenance damage capillaries, lymphatics, cells, and connective tissue leading to an acute inflammatory response.

Methods: We compared an investigational CSII catheter (IC) and a commercial CSII catheter (CC) regarding insulin absorption pharmacokinetics (PK) and tissue inflammation. The two different catheter designs were implanted into the subcutaneous tissue of six swine for 5 days. Insulin boluses were given on days 1, 3, and 5 of wear-time to assess PK. Tissue around catheters was excised and stained to visualize inflammation and morphological changes of adjacent tissue.

Results: Insulin absorption was better when infused through a $\mathrm{CC}$ with highest $C_{\max }$ and fastest $t_{\max }$ values on day 5 of catheter wear-time. Both catheter types produced high intra- and intersubject day-to-day insulin absorption variability. The IC caused significantly more tissue disruption and lead to irregular changes in tissue morphology. Both catheter types were surrounded by a layer of inflammatory tissue that varied in composition, thickness, and density over time. A catheter that was manually inserted by pushing a sharp tip through the skin caused more trauma and variability than a $90^{\circ}$ Teflon cannula with automated insertion.

Conclusions: Insulin absorption variability could be attributed to the layer of inflammatory tissue, which may function as a mechanical barrier to insulin flow into adjacent vascular tissue. The impact of the acute inflammatory tissue response on insulin absorption has to be considered in future catheter designs. A catheter that was manually inserted by pushing a sharp tip through the skin caused more trauma and variability than a $90^{\circ}$ Teflon cannula with automated insertion.
\end{abstract}

Keywords: CSII therapy, Insulin absorption variability, Inflammatory response, Adipose tissue inflammation, Insulin pharmacokinetics, CSII catheter.

\footnotetext{
${ }^{1}$ Department of Anesthesiology, Jefferson Artificial Pancreas Center, Sidney Kimmel Medical College, Thomas Jefferson University, Philadelphia, Pennsylvania.

${ }^{2}$ Division of Endocrinology and Diabetology, Department of Internal Medicine, Medical University of Graz, Graz, Austria.

${ }^{3}$ Department of Pathology, Sidney Kimmel Medical College, Thomas Jefferson University, Philadelphia, Pennsylvania.

${ }_{5}^{4}$ Animas Corporation, West Chester, Pennsylvania.

${ }^{5}$ Department of Pharmacology and Experimental Therapeutics, Sidney Kimmel Medical College, Thomas Jefferson University, Philadelphia, Pennsylvania.

(C) Jasmin R. Hauzenberger et al., 2017; Published by Mary Ann Liebert, Inc. This Open Access article is distributed under the terms of the Creative Commons License (http://creativecommons.org/licenses/by/4.0), which permits unrestricted use, distribution, and reproduction in any medium, provided the original work is properly credited.
} 


\section{Introduction}

W ORLDWIDE, $\sim 1$ MILlion people manage their diabetes with an insulin pump, rapid acting insulin, and a continuous subcutaneous insulin infusion (CSII) catheter. ${ }^{1}$ Insulin is continuously delivered through the CSII catheter at a variable basal rate between meals and during sleep. Diabetic patients deliver a bolus of insulin according to meal size, composition, insulin to carbohydrate ratio, preprandial glucose concentration, and an estimate of residual insulin-on-board. ${ }^{1-4}$ Despite recent improvements in CSII catheter design and method of insertion, the CSII catheter remains the weak link of an insulin infusion system for the management of type 1 diabetes. ${ }^{5-7}$ Patients are instructed to insert a new CSII set every 2 to 3 days because insulin absorption into the circulation becomes more variable and less reliable over time. ${ }^{6,8,9}$ Catheters are routinely replaced when a bolus dose of insulin fails to produce the expected glucose lowering effect, defined as unexplained hyperglycemia.

The mechanisms that cause variable and unreliable insulin absorption from a CSII catheter into the circulation are poorly understood. ${ }^{10-13}$ When a CSII catheter is inserted, it causes an acute inflammatory response of the adipose tissue. ${ }^{14} \mathrm{~A}$ layer of inflammatory tissue forms around each CSII cannula that contains plasma proteins, platelets, red blood cells, white blood cells, and cellular debris. ${ }^{14-16}$ The degree of inflammation is dependent on catheter material, shape, and weartime and may influence insulin absorption. ${ }^{14,17}$

The success of insulin pump therapy may further be dependent on the robustness of insertion methods to avoid issues such as catheter kinking and therefore failed delivery of insulin into the tissue. ${ }^{18,19} \mathrm{We}$ hypothesize that the flow of insulin from a CSII catheter into adjacent vascular tissue is affected by the changing composition and architecture of the inflammatory tissue layer surrounding the cannula, causing insulin absorption pharmacokinetics (PK) to be variable. We believe that this variability is further influenced by the catheter material, shape, and insertion method.

The goal of this pilot study was to evaluate the PK of lispro insulin absorption and the tissue response to two different CSII catheter materials (Teflon and a flexible metal-ceramic alloy) and designs implanted in the subcutaneous tissue of six swine for 5 days.

\section{Research Design and Methods}

We performed an observational study in six swine to evaluate the PK of insulin lispro (U-100 Humalog; Eli Lilly) infused through CSII catheters implanted for 5 days. Six commercial CSII catheters (CCs) and six investigational CSII catheters (ICs) were inserted into the subcutaneous tissue of each swine. Lispro insulin and saline were infused through the CCs and ICs for 5 days using battery powered insulin pumps and the same basal/bolus pattern of delivery. Additional CCs and ICs were filled with saline and capped (Supplementary Table S1; Supplementary Data are available online at www.liebertpub.com/dia). Insulin PK $\left(C_{\max }, t_{\max }\right.$, AUC, AUC60) following a 5-U bolus were evaluated on days 1,3 , and 5 . The tissue surrounding the 72 CSII was excised and pathologically analyzed to elucidate the relationship between the PK of insulin absorption and the inflammatory tissue response to trauma and the CSII cannula.
In vivo swine study $(\mathrm{n}=6)$

The study was performed in six nondiabetic ambulatory female swine $(68.5 \pm 3.6 \mathrm{~kg})$. The protocol was approved by the Institutional Animal Care \& Use Committee of Thomas Jefferson University. General anesthesia and aseptic surgical technique were used to implant central venous catheters (CVC, CP2 vascular access ports; Access Technologies, IL) into the left innominate vein (for blood sample acquisition) and the distal superior vena cava (for glucose infusion). The CVC ports were flushed every 1-3 days using a Huber needle and low-dose heparin solution. One week later, each swine was given general anesthesia and six CCs (Inset $^{\mathrm{TM}}$; UnoMedical, Denmark) and six ICs were inserted into the subcutaneous tissue of the abdomen using an aseptic technique according to the manufacturer's instructions. In total, 72 CSII were implanted in six swine.

The CC had a stable plastic platform with an adhesive base for attachment to the skin. The $6 \mathrm{~mm}$ Teflon cannula was inserted at a $90^{\circ}$ angle through the skin and subcutaneous tissue over a sharp 27-gauge steel needle. Insertion force was applied to the catheter using a spring-loaded introducer. The needle was removed leaving the Teflon cannula within the subcutaneous tissue throughout the 5-day study (Supplementary Fig. S1, left). The IC had a stable plastic platform with an adhesive base for attachment to the skin. The platform was an open clam-shell design with a side hinge. Closing the platform manually guided the curved cannula through the skin and into the subcutaneous tissue at an insertion angle of $\sim 60^{\circ}$. The needle was thin and slightly flexible with a sharp tip (Supplementary Fig. S2, right). The IC cannula remained within the subcutaneous tissue throughout the 5-day study. CSII catheters were carefully inspected to confirm correct insertion through the skin and into the subcutaneous tissue.

Two CCs and two ICs were connected to insulin pumps (OneTouch Ping; Animas Corporation, West Chester, PA) containing rapid acting lispro insulin. Two CCs and two ICs were connected to insulin pumps containing saline solution. The remaining two CCs and two ICs were primed with saline and did not receive an infusion (Supplementary Table S1). CSII were secured with Tegaderm ${ }^{\mathrm{TM}}$ adhesive bandages and the eight insulin pumps were secured within the pockets of a custom vest (Lomir Biomedical, Inc., Supplementary Fig. S2). Insulin lispro was continuously infused through the four CSII catheters at a low basal rate $(0.2 \mathrm{U} / \mathrm{h} /$ catheter $=0.8 \mathrm{U} / \mathrm{h})$. Insulin and saline were infused using the same basal/bolus pattern throughout the 5-day study.

The subcutaneous tissue glucose concentration was monitored using commercial glucose sensors (SEVEN PLUS; Dexcom, Inc.) calibrated using CVC blood samples and a reference glucose analyzer (YSI-2300STAT Plus ${ }^{\mathrm{TM}}$; Yellow Springs Instruments). A battery powered pump (Ipump Pain Management System, Baxter MN) continuously infused a solution of $50 \%$ dextrose into a CVC between PK studies to minimize the risk for hypoglycemia.

\section{Insulin PK}

PK studies were performed on days 1, 3, and 5 after CSII insertion. On day 1, animals recovered from general anesthesia for $\sim 2 \mathrm{~h}$ before starting the PK study. Blood was sampled from a CVC every $10 \mathrm{~min}$ for $\sim 2 \mathrm{~h}$, followed by 
every $15 \mathrm{~min}$ for $1 \mathrm{~h}$ before administering the second bolus and repeating the sampling schedule. When blood sample acquisition from a CVC was not possible, samples were obtained from the alternate $\mathrm{CVC}$ or occasionally omitted. The swine were able to stand up, lie down, and consume food (apples, biscuits) and water during the PK study. The concentration of blood glucose (BG) was measured in duplicate using the YSI analyzer. Samples were centrifuged to plasma and stored at $-80^{\circ} \mathrm{C}$ for subsequent insulin assay. A stable baseline was established for $\sim 30 \mathrm{~min}$ (three to five $\mathrm{BG}$ values).

We then infused a 5-U bolus of insulin into a $\mathrm{CC}$ or an IC in a randomized order. The concentration of $\mathrm{BG}$ was maintained between 100 and $160 \mathrm{mg} / \mathrm{dL}$ by adjusting an intravenous infusion of $20 \%$ dextrose every $5-10 \mathrm{~min}$ for $3 \mathrm{~h}$. A second baseline was then established for $\sim 30 \mathrm{~min}$ to ensure that BG levels have returned to baseline values after the morning insulin bolus, followed by a 5-U bolus of insulin infused into the alternate CSII catheter. The afternoon PK study ended $\sim 3 \mathrm{~h}$ later. Thus, two PK studies were performed on days 1, 3, and 5 in the same swine using the same CC and IC each day.

The concentration of lispro insulin was measured in plasma samples by PreClinOmics, Inc. (Indianapolis, IN) using a porcine insulin ELISA and an Iso-insulin ELISA (Mercodia AB, Uppsala, Sweden). The lispro insulin concentration was calculated by subtracting the porcine insulin from the total insulin concentration. A baseline was calculated for each PK study averaging the last three to five values before the bolus was administered $(t=0)$, and subtracting this value from insulin concentrations at each time point. Maximal plasma insulin levels $\left(C_{\max }\right)$ and time-to-peak $\left(t_{\max }\right)$ were determined.

The areas under the curve (AUC) of insulin concentration (baseline subtracted) versus time were calculated between the time of bolus and $60 \mathrm{~min}$ (AUC60) and $160 \mathrm{~min}$ (AUC) after the bolus. We applied the linear trapezoidal method using the PKSolver add-in for Microsoft Excel. ${ }^{20}$ For a given time interval $\left(t_{2}-t_{1}\right)$, the integral was calculated by $1 / 2 \cdot\left(C_{1}+\right.$ $\left.C_{2}\right) \cdot\left(t_{2}-t_{1}\right)$. AUC equals the sum of the integrals. The interand intrasubject coefficient of variation $(\mathrm{CV})$ was calculated for AUC, AUC60, $C_{\max }$, and $t_{\max }$ for each day and across all study days.

\section{Tissue histology}

The swine were euthanized after completion of the third PK study on day 5. A $50 \mu \mathrm{L}$ bolus of methylene blue dye was then infused into the CCs and ICs to determine whether dye migrated onto the skin surface. The skin and subcutaneous tissue surrounding the 72 catheters were excised and fixed in $10 \%$ formalin for 3 days. The tissue was grossed and processed using a long dehydration protocol for fatty tissue. ${ }^{21}$ Specimens were sectioned perpendicular or parallel to the skin surface depending on the location and angle of the cannula in the excised tissue specimen. Four-micrometerthick tissue sections were stained with hematoxylin and eosin (nuclei are stained blue/purple, extracellular matrix [ECM] and cytoplasm are stained in pink), Masson's trichrome (collagen/connective tissue is stained blue, muscle fibers and erythrocytes are stained bright red, and cytoplasm is stained pink), and a reticulin stain (type III collagen is stained silver).

A surgical pathologist analyzed the stained tissue for no, mild, moderate, or severe (grades $0,1,2$, or 3 , respectively) hemorrhage, reticular fiber disruption, fibrin deposition, fat necrosis, and collagen deposition compared with unaffected tissue. This grading system was newly established by the lead pathologist of this study who predefined these criteria before analyzing all samples. The pathologist remained blinded throughout the study. The size of the debris field was measured $(\mathrm{mm})$ using the Aperio ScanScope image capture device and ImageScope software (Leica Biosystems). Topography of tissue planes was considered regular if subcutaneous tissue was pushed down evenly in the direction of the cannula tip and irregular or intermediate otherwise. Irregular or regular reservoir geometry described the shape of the debris field surrounding the catheter tip.

Fisher's exact test was used to evaluate the differences in histology profiles of CCs and ICs. A chi-squared test was applied to analyze differences in methylene blue dye leakage.

\section{Results}

\section{Tissue histology surrounding a CSII catheter}

In general, the tissue surrounding the CSII cannula on day 5 of implantation resembled a clean surgical wound with a foreign body, rather than normal dermis and subcutaneous tissue (Supplementary Fig. S3). Cells, capillaries, lymph vessels, connective tissues (collagen, elastin, reticular fibers), and ECM were damaged along the path of cannula insertion. Thrombus formed around many of the cannulas due to damaged arterioles, capillaries, and venules (Fig. 1A center). All of the specimens had regions of adipose cell necrosis (Fig. 1A-D) and acute inflammation. Although not visualized, lysed adipose cells would have released their contents (cytoplasm, nucleus, organelles, and triglycerides) into the wound.

Neutrophils, macrophages, fibroblasts, and lymphocytes migrated into the areas of tissue damage from the local capillaries (dense purple and pink areas within subcutaneous tissue in hematoxylin and eosin sections, Fig. 1A-D, Supplementary Figs. S4-S15). Thrombus and immune cells produced a layer of fibrin and acute inflammatory tissue that partially or completely surrounded the implanted cannula (Fig. 1A, B, center, Supplementary Figs. S6-S17). Fibroblasts produced a variable amount of fresh collagen (stained light blue in the trichrome stains compared to the darker blue of mature collagen) that added thickness and density to this surrounding layer of inflammatory tissue (Fig. 1A-C, center, Supplementary Figs. S6-S17).

Several specimens showed a downward migration of epidermis/dermis into the insertion channel (Supplementary Figs. S8-S10). Tables 1 and 2 summarize the surgical pathologist's description of the tissue response to CSII implantation for 5 days ( $n=72 ; 36 \mathrm{CCs}$ and $36 \mathrm{ICs})$. The CCs elicited significantly less reticular fiber disruption, fat necrosis, hemorrhage at the cannula tip, a regular tissue topography, and a smaller debris field compared with the ICs. The ICs produced a larger debris field with irregular topography of tissue planes and irregular reservoir geometry $(P<0.001)$. The layer of inflammatory tissue surrounding the $\mathrm{CC}$ and IC cannula varied in thickness, density, composition, and continuity.

There was no statistically significant difference in fibrin or collagen deposition at the cannula tip. The tissue histopathology surrounding the CSII infused with lispro insulin had a greater amount of fibrin in the reservoir, but was generally 

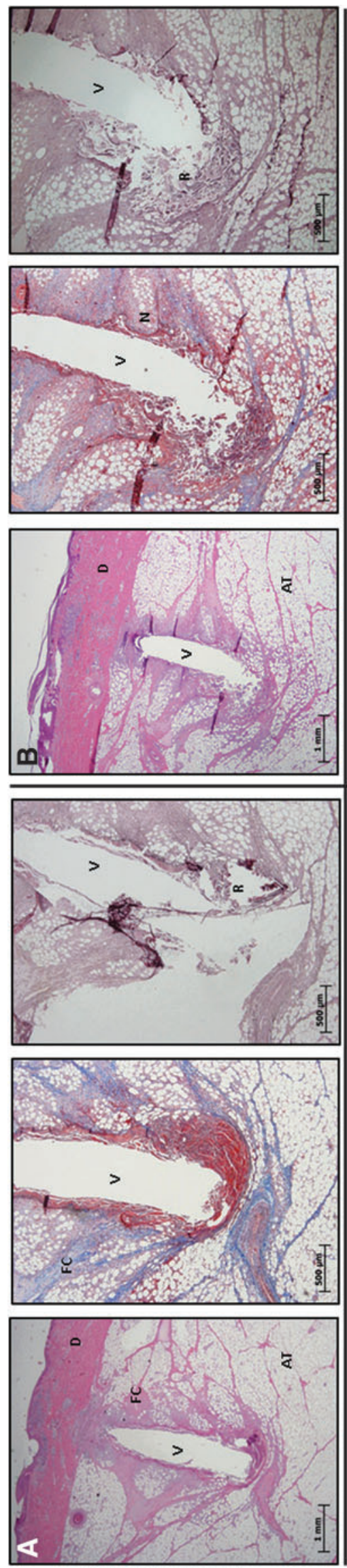

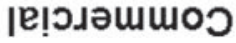
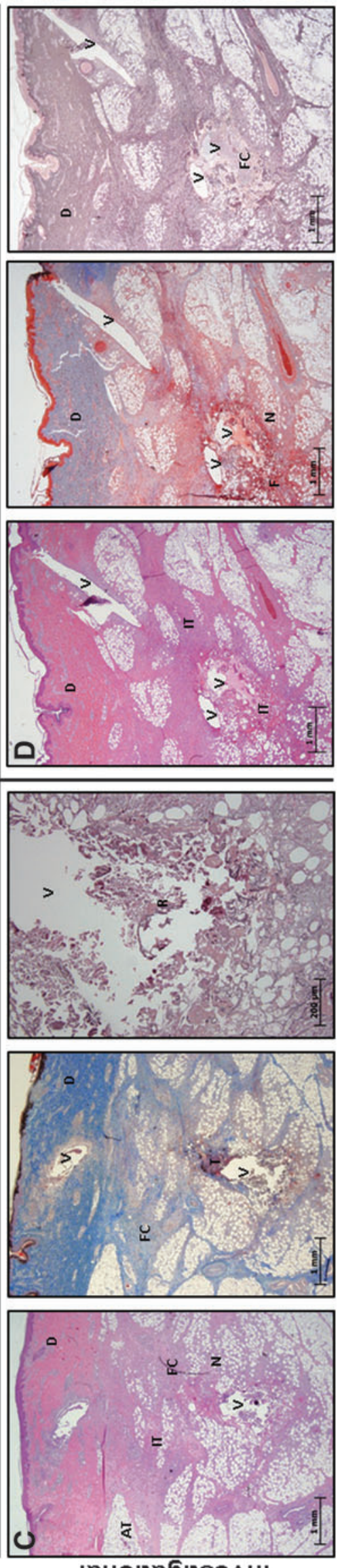

|eนо!̣อб!̣sว^u|

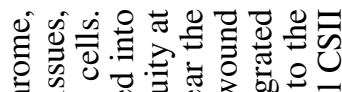

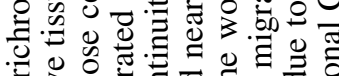

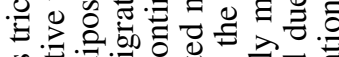
n. 음 뭉 造

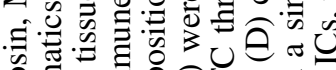
o 0 政

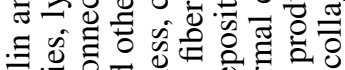

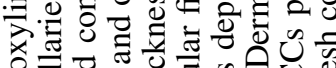

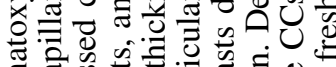

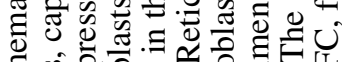
舟

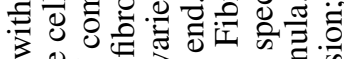

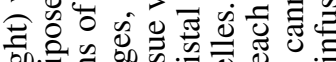

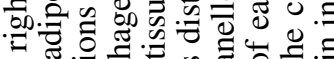
응 500 응

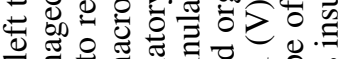

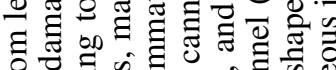

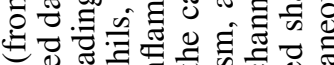
政 : क्ष

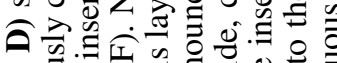
U. o o

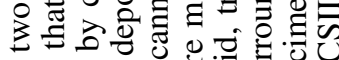

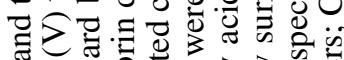

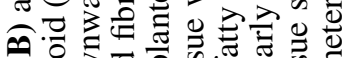

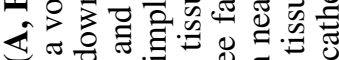
u. U 중요

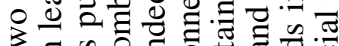

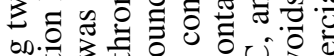
on. $3=0$ 잉

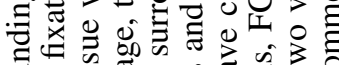

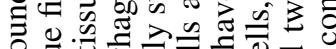
要 ज. 两过 응

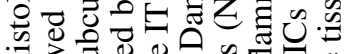

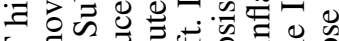

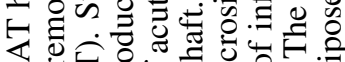

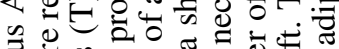
of

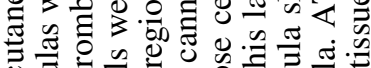

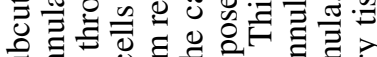

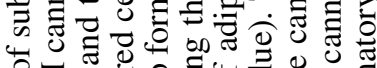
년 은․ㅡㄹ

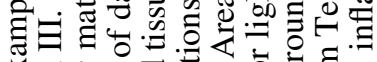

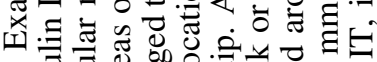
-

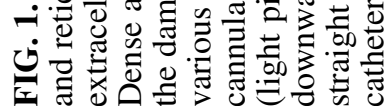


Table 1. Tissue Histology Data

\begin{tabular}{|c|c|c|c|c|c|c|}
\hline & CSII catheter & None & Mild & Moderate & Severe & \\
\hline \multirow[t]{2}{*}{ Reticular fiber disruption } & $\mathrm{CC}$ & $1(2.8 \%)$ & $29(80.6 \%)$ & $6(16.7 \%)$ & 0 & ** \\
\hline & IC & 0 & $6(16.7 \%)$ & $9(25.0 \%)$ & $21(58.3 \%)$ & \\
\hline \multirow{2}{*}{ Fibrin deposition in reservoir } & $\mathrm{CC}$ & $1(2.8 \%)$ & $10(27.8 \%)$ & $15(41.7 \%)$ & $10(27.8 \%)$ & \\
\hline & IC & 0 & $8(22.2 \%)$ & $21(58.3 \%)$ & $7(19.4 \%)$ & \\
\hline \multirow{2}{*}{ Collagen deposition at tip } & $\mathrm{CC}$ & $4(11.1 \%)$ & $26(72.2 \%)$ & $6(16.7 \%)$ & 0 & \\
\hline & IC & $1(2.8 \%)$ & $23(63.9 \%)$ & $11(30.6 \%)$ & $1(2.8 \%)$ & \\
\hline \multirow{2}{*}{ Fat necrosis } & $\mathrm{CC}$ & $1(2.8 \%)$ & $22(61.1 \%)$ & $13(36.1 \%)$ & 0 & \\
\hline & IC & 0 & $7(19.4 \%)$ & $14(38.9 \%)$ & $15(41.7 \%)$ & \\
\hline \multirow{2}{*}{ Hemorrhage at tip base } & $\mathrm{CC}$ & $1(2.8 \%)$ & $27(75.0 \%)$ & $8(22.2 \%)$ & & * \\
\hline & IC & $1(2.8 \%)$ & $17(47.2 \%)$ & $17(47.2 \%)$ & $1(2.8 \%)$ & \\
\hline Changes in tissue morphology & & Regular & Intermediate & Irregular & & \\
\hline \multirow[t]{2}{*}{ Reservoir geometry } & $\mathrm{CC}$ & 29 (82.9\%) & - & $6(17.1 \%)$ & & $* *$ \\
\hline & IC & $11(30.6 \%)$ & - & $25(69.4 \%)$ & & \\
\hline \multirow{2}{*}{$\begin{array}{l}\text { Topography of tissue planes } \\
\text { along insertion }^{\mathrm{a}}\end{array}$} & $\mathrm{CC}$ & $30(85.7 \%)$ & $5(14.3 \%)$ & 0 & & \\
\hline & IC & $1(2.8 \%)$ & $19(52.8 \%)$ & $16(44.4 \%)$ & & \\
\hline \multicolumn{7}{|c|}{ Depth $(m m) \pm S D$} \\
\hline \multirow[t]{2}{*}{ Debris field (mean) } & $\mathrm{CC}$ & $3.2 \pm 1.1$ & & & & $*$ \\
\hline & IC & $4.9 \pm 1.4$ & & & & \\
\hline
\end{tabular}

Values in brackets are a percent of $36 \mathrm{CCs}$ and 36 ICs total.

${ }^{a}$ Tissue morphology for Swine1-CC1 was not evaluated due to incomplete/superficial insertion of catheter; ***P<0.001.*P<0.05 significant difference between catheter types.

CC, commercial CSII catheter; CSII, continuous subcutaneous insulin infusion; IC, investigational CSII catheter.

similar to the histology surrounding catheters infused with saline or not infused (Table 2 and Supplementary Table S2).

\section{Insulin PK}

Table 3 summarizes the PK data for the CCs and ICs infused with a 5-U insulin bolus. CV for intersubject (between) and intrasubject (within) variability are summarized in Table 4 and Supplementary Table S3. The mean AUC and $C_{\max }$ were higher and $t_{\max }$ shorter for insulin administered through the CCs compared to the ICs. However, these data could not be analyzed for statistical significance due to the small number of studies. Data for swine 1 were excluded before PK analysis, due to faulty insertion (kinking) causing inadequate penetration into the subcutaneous tissue, leading to limited insulin absorption. We furthermore could not calculate the AUC for the CC in swine 6, as we were unable to collect blood samples $20 \mathrm{~min}$ after bolus administration for a period of $1.5 \mathrm{~h}$ in this animal.

The averaged PK data for days 1,3 , and 5 are shown in Figure 2 and the individual PK curves are shown in Figure 3. All of the CCs and ICs produced a high intrasubject and intersubject day to day PK variability (Table 4$)$. The other five CCs produced the fastest insulin absorption $\left(t_{\max }=12.0\right.$

Table 2. Tissue Histology Data According to Type of Infusion (Insulin, Saline, None)

\begin{tabular}{lllrrr}
\hline & Infusion & None & \multicolumn{1}{c}{ Mild } & Moderate & \multicolumn{1}{l}{ Severe } \\
\hline Reticular fiber disruption & Insulin & $1(4.2)$ & $9(37.5)$ & $6(25.0)$ & $8(33.3)$ \\
& Saline & 0 & $13(54.2)$ & $3(12.5)$ & $8(33.3)$ \\
\multirow{3}{*}{ Fibrin deposition in reservoir } & None & 0 & $13(54.2)$ & $6(25.0)$ & $5(20.8)$ \\
& Insulin & $1(4.2)$ & $2(8.3)$ & $11(45.8)$ & $10(41.7)$ \\
& Saline & 0 & $9(37.5)$ & $11(45.8)$ & $4(16.7)$ \\
Collagen deposition at tip & None & 0 & $7(29.7)$ & $14(58.3)$ & $3(12.5)$ \\
& Insulin & $2(8.3)$ & $16(66.7)$ & $5(20.8)$ & $1(4.2)$ \\
& Saline & $2(8.3)$ & $16(66.7)$ & $6(25.0)$ & 0 \\
Fat necrosis & None & $1(4.2)$ & $17(70.8)$ & $6(25.0)$ & 0 \\
& Insulin & $1(4.2)$ & $5(20.8)$ & $12(50.0)$ & $6(25.0)$ \\
\multirow{3}{*}{ Hemorrhage at tip base } & Saline & 0 & $14(58.3)$ & $5(20.8)$ & $5(20.8)$ \\
& None & 0 & $10(41.7)$ & $10(41.7)$ & $4(16.7)$ \\
& Insulin & $1(4.2)$ & $13(54.2)$ & $10(41.7)$ & 0 \\
& Saline & $1(4.2)$ & $15(62.5)$ & $7(29.2)$ & $1(4.2)$ \\
& None & 0 & $16(66.7)$ & $8(33.3)$ & 0
\end{tabular}

Values in brackets are a percent of $36 \mathrm{CCs}$ and $36 \mathrm{ICs}$ total; $* P<0.05$ significant difference between infusion types. 
Table 3. Mean Values for AUC, AUC60, $C_{\text {max }}$, And $T_{\text {max }}$ For Both Types OF CSII CATHETERS ON DAYS 1, 3, AND 5

\begin{tabular}{lccccc}
\hline Catheter type & Day & $\mathrm{AUC}\left(\frac{\mathrm{m} U}{\mathrm{~L}} \mathrm{~h}\right)$ & $\mathrm{AUC60}\left(\frac{\mathrm{mU}}{\mathrm{L}} \mathrm{h}\right)$ & $\mathrm{C}_{\max }\left(\frac{\mathrm{mU}}{\mathrm{L}}\right)$ & $\mathrm{t}_{\mathrm{max}}(\mathrm{min})$ \\
\hline $\mathrm{CC}\left(n=5^{\mathrm{a}}\right.$ swine $)$ & 1 & $82.7 \pm 37.6$ & $50.9 \pm 12.9$ & $90.7 \pm 26.8$ & $35.0 \pm 17.3$ \\
& 3 & $63.1 \pm 22.8$ & $47.0 \pm 25.6$ & $73.9 \pm 41.0$ & $20.0 \pm 12.2$ \\
& 5 & $71.1 \pm 29.4$ & $54.9 \pm 20.8$ & $114.7 \pm 30.1$ & $12.0 \pm 4.5$ \\
$\mathrm{IC}(n=6$ swine $)$ & 1 & $68.5 \pm 36.0$ & $44.3 \pm 23.2$ & $120.0 \pm 59.3$ & $43.3 \pm 28.8$ \\
& 3 & $63.1 \pm 51.8$ & $42.7 \pm 40.0$ & $115.0 \pm 86.2$ & $20.0 \pm 6.3$ \\
& 5 & $40.1 \pm 37.6$ & $29.0 \pm 31.3$ & $105.1 \pm 87.7$ & $33.3 \pm 18.6$ \\
\hline
\end{tabular}

Data are provided as mean \pm SD.

${ }^{\mathrm{a}} \mathrm{PK}$ from swine 1 excluded due to incomplete insertion of $\mathrm{CC} 1$ catheter.

AUC, areas under the curve; PK, pharmacokinetics.

$\pm 4.5 \mathrm{~min})$, the highest plasma insulin concentration $\left(C_{\max }=\right.$ $114.7 \pm 30.1 \mathrm{mU} / \mathrm{L})$, and the highest AUC60 (54.9 \pm 20.8 $\mathrm{mU} / \mathrm{L} \cdot \mathrm{h})$ on day 5 of implantation. Insulin absorption from the CCs and was least variable on day 5 and most variable on day 1 (Fig. 2 and Table 4). Two CCs produced low and delayed insulin absorption on day 1 , followed by higher insulin absorption on subsequent days. The six ICs produced the highest AUC60, AUC, and $C_{\max }$ on day 1, the fastest insulin absorption on day 3 , and the lowest AUC60, AUC, and $C_{\max }$ on day 5. Five of the six ICs produced a lower AUC on day 5 compared with day 3 (Table 3). Insulin absorption from the ICs was least variable (range 34-124 mU/L*h, intersubject $\mathrm{CV}=52.5 \%$ ) on day 1 and most variable on day 3 (range 9$132 \mathrm{mU} / \mathrm{L}^{*} \mathrm{~h}$, intersubject $\mathrm{CV}=93.8 \%$ ). We were unable to detect a statistical relationship between the observed histology results and insulin absorption PK due to the small sample size and high variability. Supplementary Table S4 gives an overview over the histology data and corresponding PK values.

Insulin pump occlusion alarms, dye leakage, and insulin PK

The CC of swine 1 used for the PK study did not insert fully into the subcutaneous tissue, kinked, leaked a large amount of dye onto the skin surface, and produced very limited insulin absorption into the circulation (Fig. 2B). No other CC leaked dye onto the skin surface (35/36). One of the CCs leaked a large amount of dye into the hub (3\%), five CCs leaked a small amount into the hub (14\%), and four CCs had a pump occlusion alarm (11\%). Dye leakage and occlusion alarms occurred in CCs that were infused with insulin lispro, saline, and not infused (Supplementary Table S5). The CC of swine 2 used for the PK study produced a pump occlusion alarm on day 3 only. No other CC used for the PK study developed an occlusion alarm. The ICs of swine 1, 2, 3, and 4 used for the PK study produced one or more occlusion alarms. The IC of swine 1, 2, and 6 leaked dye into the CSII hub and produced limited insulin absorption on days 3 and/or 5 (Fig. 2D).

\section{Discussion}

To our knowledge, this is the first study comparing insulin PK and tissue histopathology surrounding two different types of CSII catheters in the same swine while infusing insulin, saline, or no infusion. The commercial and ICs had distinct designs, materials, and methods of insertion that produced a significant difference in the inflammatory tissue response and distinct patterns of insulin absorption. A surgical pathologist analyzed the tissue specimens using an objective grading system with each swine acting as its own control. The study was limited by the small sample size and the difficulty in controlling variables that may affect insulin absorption into the subcutaneous vascular tissue in awake swine, such as temperature, activity level, and food intake. Many CCs and ICs produced one or more pump occlusion alarms, leaked dye/insulin into the hub or onto the skin surface. In addition, histology did not always provide a complete picture of the tissue surrounding the CSII cannula, as localization of the full insertion channel was sometimes difficult. At the time of plasma insulin measurement, no lispro-specific ELISA was

TABle 4. COEFFICIENTS OF VARIATION FOR INTER- AND INTRASUBJect VARIABILITy For EACH DAY AND Over All Days

\begin{tabular}{|c|c|c|c|c|c|c|}
\hline$C V$ type & Catheter & Day & $C V A U C, \%$ & $C V A U C 60, \%$ & $C V \mathrm{C}_{\max }, \%$ & $C V \mathrm{t}_{\max }, \%$ \\
\hline \multirow[t]{3}{*}{ Between animals } & $\mathrm{CC}$ & 1 & 45.6 & 25.3 & 29.5 & 49.5 \\
\hline & $\mathrm{CC}$ & 3 & 36.1 & 54.5 & 55.6 & 61.2 \\
\hline & $\mathrm{CC}$ & 5 & 41.3 & 38.0 & 26.2 & 37.3 \\
\hline \multirow[t]{3}{*}{ Between animals } & IC & 1 & 52.5 & 52.5 & 49.4 & 66.4 \\
\hline & IC & 3 & 82.1 & 93.7 & 75.0 & 31.6 \\
\hline & $\mathrm{IC}$ & 5 & 93.8 & 107.9 & 83.4 & 55.9 \\
\hline \multirow[t]{2}{*}{ Between animals } & $\mathrm{CC}$ & All & 13.7 & 7.8 & 22.0 & 52.3 \\
\hline & IC & All & 26.4 & 21.7 & 6.7 & 36.3 \\
\hline \multirow[t]{2}{*}{ Within animals } & $\mathrm{CC}$ & All & 30.8 & 25.5 & 37.0 & 39.2 \\
\hline & $\mathrm{IC}$ & All & 69.6 & 83.8 & 49.5 & 55.5 \\
\hline
\end{tabular}

$\mathrm{CV}$, coefficient of variation. 

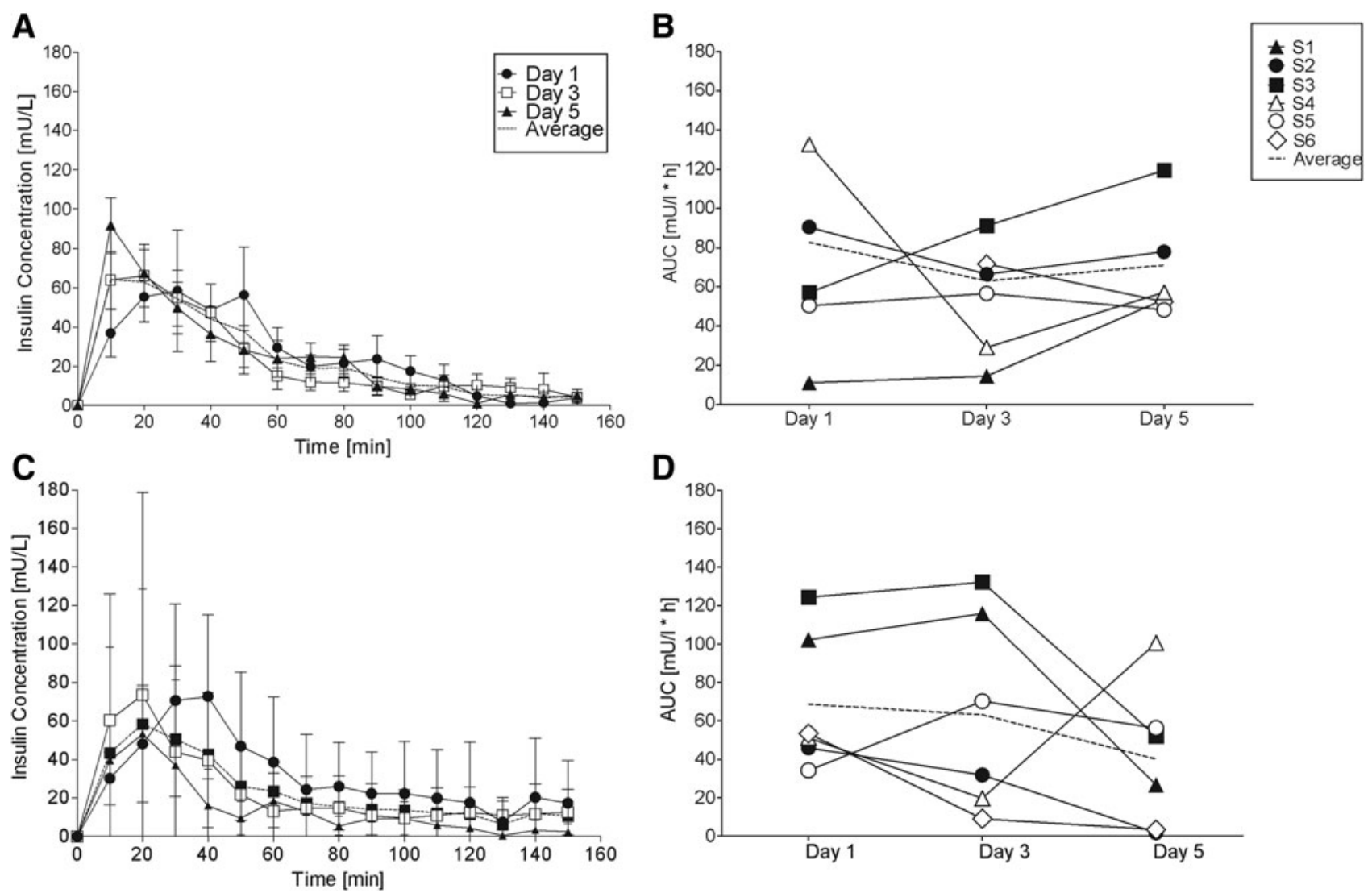

FIG. 2. Insulin concentration versus time curves $(\mathbf{A}, \mathbf{C})$ and area under the insulin absorption curve (AUC, B, D) for CC (commercial) and IC (investigational) CSII catheters. (A) CC and (C) IC show average plasma insulin concentration curves on days 1, 3, and 5 of catheter wear-time. Dotted lines represent the average \pm SD for the three PK studies. (B) CC and (D) IC show area under the insulin absorption curve (AUC) over $2.5 \mathrm{~h}$. Dotted line represents the average AUC values for six swine on days 1,3 , and 5 (data from swine 6 on day 1 were excluded because we were unable to obtain blood samples). AUC, areas under the curve; PK, pharmacokinetics.

commercially available and insulin concentrations were calculated indirectly by subtracting porcine insulin from total insulin content. Unfortunately, this indirect calculation adds to the calculated intra- and intersubject variability.

An ideal CSII catheter would produce fast and consistent insulin PK for an extended period of time (4-14 days) with no occlusions, leaks, or infections. Patients are currently educated to replace their CCs every 2 to 3 days to minimize the risk of infection and because insulin absorption from the subcutaneous tissue into the circulation becomes more variable and less reliable over time. Patients commonly experience an insulin bolus that fails to produce the expected glucose lowering effect, leading to persistent hyperglycemia. ${ }^{6,19}$ Insulin absorption (PK) in this swine study was variable when insulin was infused through either type of CSII catheter on days 1, 3, and 5. This observation is consistent with published animal studies, human clinical trials, and routine clinical care. ${ }^{5,6,22,23}$ Of interest, the $\mathrm{CC}$ s produced the fastest insulin absorption, the highest plasma insulin concentration, and the greatest AUC60 on day 5 of implantation. Insulin absorption from the CCs was least variable on day 5 and most variable on days 1 and 3 . The day 5 observations are of interest, as current recommendations do not recommend the patient to wear a CSII set until day 5, when insulin absorption may recover. Studies have shown that some patients indeed successfully wear CSII catheters up to 7 days. ${ }^{19,24}$ In contrast, the ICs produced the highest AUC, AUC60, and $C_{\max }$ on day 1 , the fastest $t_{\max }$ on day 3 , and the lowest AUC, AUC60, and $C_{\max }$ on day 5. Figures 1 and 2 illustrate the importance of reviewing the individual PK curves from each experiment to acknowledge the large dose-to-dose and dayto-day variability. The individual PK curves are highly variable in contrast with the average PK curves. Ten of the $36 \mathrm{PK}$ studies resulted in a limited and/or delayed insulin absorption curve. The three ICs that produced low insulin absorption on day 5 had a pump occlusion alarm and/or leaked dye into the hub. The decreased uptake of insulin when administered through the IC may primarily be explained by issues in the connector between catheter and tubing. Methylene blue dye often accumulated in the hub indicating a technical obstruction of insulin flow.

The tissue response around CCs was characterized by a central area of adipose tissue debris surrounded by a layer of thrombus infiltrated with immune cells. Many of the specimens had a continuous or near-continuous layer of inflammatory tissue surrounding the CSII cannula, while other specimens had a discontinuous layer with normal adipose tissue adjacent to the CSII cannula. Compared with the tissue response to IC implantation, the tissue layer surrounding the Teflon cannula had more regular connective tissue topography, more regular reservoir geometry, a smaller debris field, less reticular fiber disruption, less fat necrosis, and less hemorrhage within the 
A
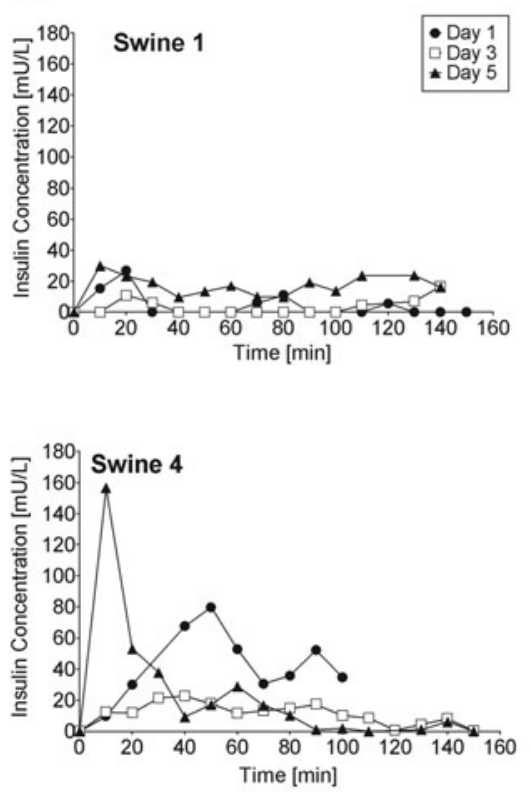
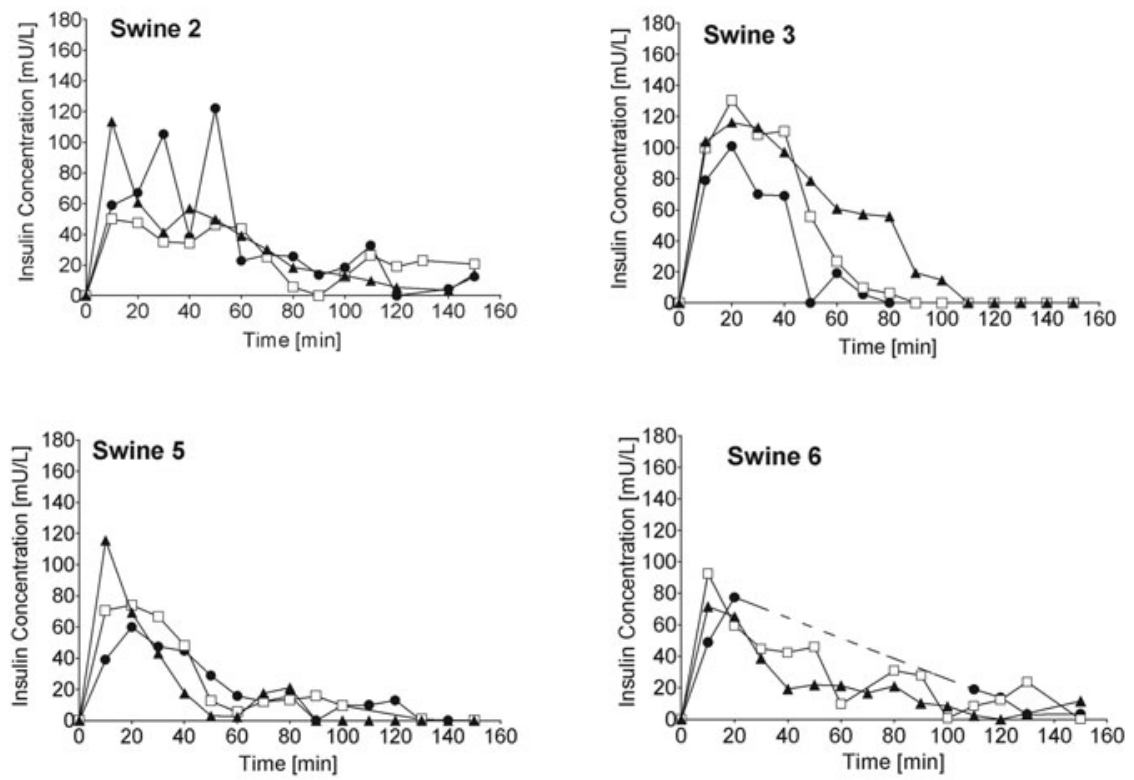

B
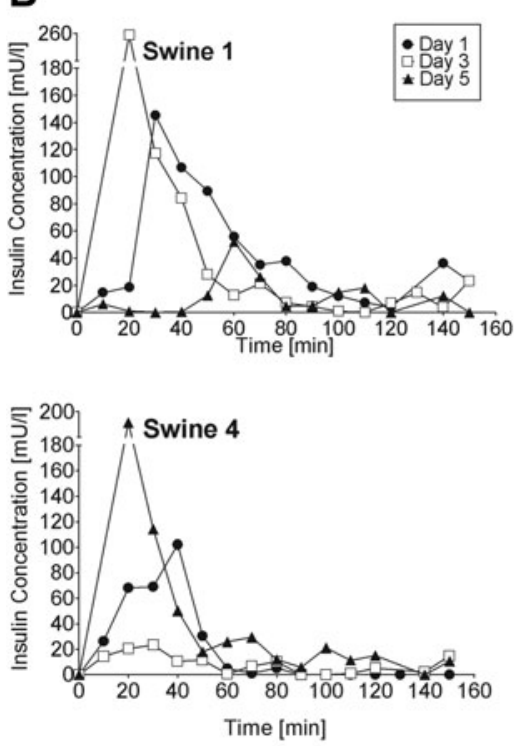
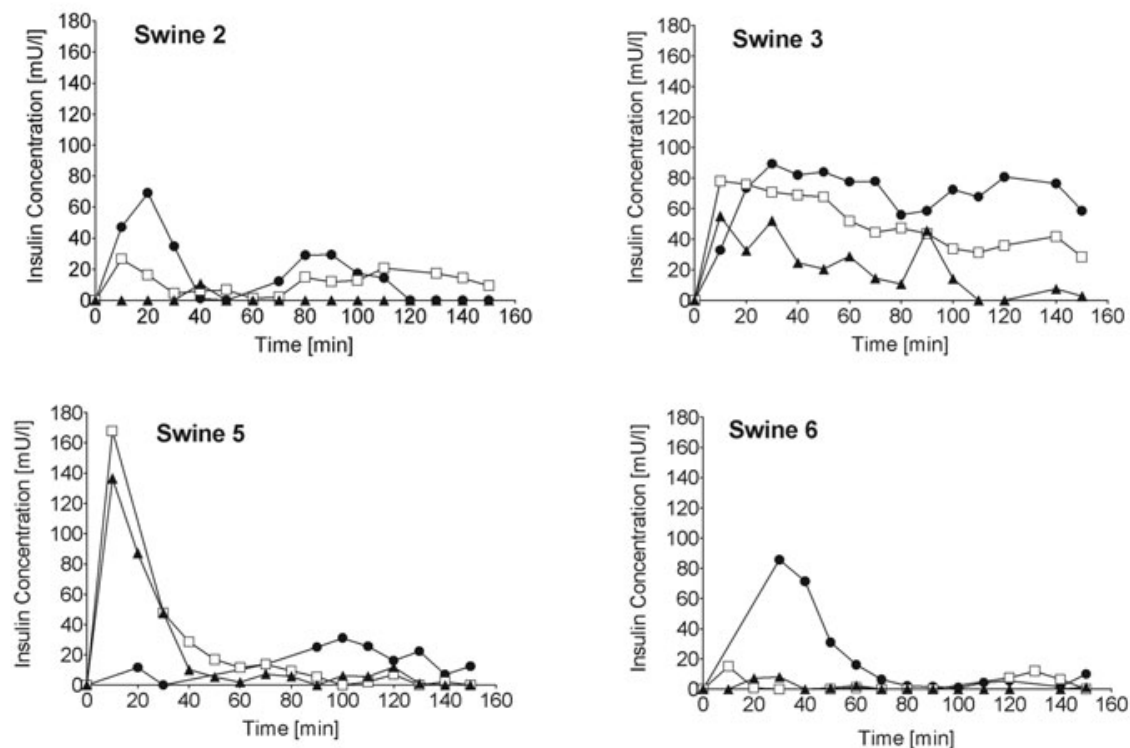

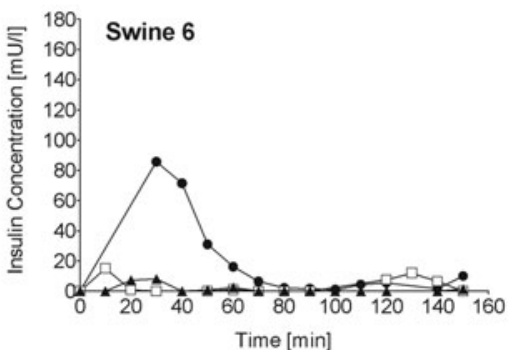

FIG. 3. Individual plasma insulin concentration curves for six swine on days 1,3 , and 5 starting at the time of a $5 \mathrm{U}$ insulin bolus infusion $(t=0)$ using (A) CCs and (B) ICs. (See Supplementary Figs. S16 and S17 for corresponding CSII catheter photos and tissue histology photos.)

reservoir. The shape of the IC possibly contributed substantially to the extent of trauma due to its sharp tip, which may have continuously disrupted tissue in the vicinity. Round, soft shapes are known to be better tolerated that sharp edges. ${ }^{17,25}$ In general, the ICs produced a similar, yet more pronounced, tissue response characterized by a central core of adipose tissue debris surrounded by a layer of fibrin thrombus infiltrated with inflammatory cells. We did not observe a difference in tissue response between infusion types, except for increased fibrin when insulin was infused.

Although the inflammatory response may be different from humans, the swine has been described as the most adequate model for human wound healing. ${ }^{26-29}$ Like humans it has a thick epidermis (70-150 $\mu \mathrm{m})$, sparse body hair, and a similar composition of the skin lipid layer. ${ }^{26,29}$ The subcutaneous adipose tissue of the swine has a similarly high elastic and collagen fiber content and the animals show a healing mechanism comparable to humans. ${ }^{26,27,29}$

When insulin is infused, an insulin pump produces a hydrostatic pressure differential between the inside of the CSII cannula and the adjacent subcutaneous tissue, causing insulin to flow into the tissue along the path of least resistance. Slow increases and abrupt decreases in insulin pump back pressure suggest that a bolus dose of insulin may accumulate within the layer of inflammatory tissue, distend the tissue, and then abruptly travel into adjacent tissue through a pathway with 
lower resistance. ${ }^{30}$ Insulin may flow into the connective tissue septa that surround the adipose cells, remain within the surrounding layer of inflammatory tissue, and/or flow upward along the cannula shaft onto the skin surface. ${ }^{30,31}$ We hypothesize that a layer of inflammatory tissue that is thick, dense, and/or continuous may prevent or delay insulin from reaching the adjacent vascular tissue. Insulin may travel through one or more holes and defects in the layer of inflammatory tissue when the hydrostatic pressure exceeds the resistance to flow. Results from this study indicate faster and better absorption of insulin on day 5, however, with a fairly high interindividual $\mathrm{CV}$ of $41 \%$ for the AUC of the commercial and $94 \%$ for the investigational catheter. The intrapatient $\mathrm{CV}$ of $37 \%$ for $C_{\max }$ and $39 \%$ for $t_{\max }$ are comparable with recently published human data. ${ }^{32}$ This high variability may be explained by the inconsistency of the mechanical inflammatory layer surrounding the cannula of a CSII catheter. Furthermore, the acute inflammatory response and the infusion of insulin may directly increase local blood flow, ${ }^{33-38}$ which may contribute to increased insulin uptake on day 5 of catheter wear-time.

Numerous factors can affect the efficiency and time course of insulin absorption into the circulation. One of them being failed insertion of the CSII catheter. The clam-shell mechanism of the IC was sometimes difficult to handle and the insertion angle of the cannula was not consistent among samples. One CC kinked below the skin, leading to inadequate insulin delivery. Both manual and supported insertions are prone to insertion failure and the optimal insertion angle is not always achieved. Ideally, the insertion of a catheter is swift and easy and the insertion angle reproducible. Insulin absorption can further be negatively influenced by insulin traveling upward onto the skin due to an obstruction of insulin flow into the adjacent tissue. We saw that issues with the catheter hub can lead to physical obstructions of insulin flow into the catheter and tissue. When unnoticed by the patient, blood glucose control may become challenging.

In conclusion, we found substantial differences in the inflammatory response to two different catheter shapes and materials and an increase in intra- and interindividual variability of insulin absorption over catheter wear-time. Maximum insulin plasma concentration levels did not change or increased with wear-time. A catheter that was manually inserted by pushing a sharp tip through the skin caused more trauma and variability than a $90^{\circ}$ Teflon cannula with automated insertion.

Additional animal and human studies are needed to better understand the effects of initial tissue damage and ongoing tissue damage on the composition, thickness, density, and continuity of the layer of inflammatory tissue that surrounds a CSII cannula; and how this immune response affects the rate and precision of insulin absorption over time. The impact of the acute inflammatory tissue response on insulin absorption may have to be considered in future catheter designs.

\section{Acknowledgments}

We thank the Thomas Jefferson University scientists Boris Mraovic, MD, Jung-won Park, MD, Ali Alazog, MD, Judith Daviau, DVM, Cynthia Lang, DVM, Joseph Altemus, and Evelyn Skoumbourdis for their assistance with data collection in ambulatory swine, and Beate Boulgaropoulos, MD
(Department of Internal Medicine, Division of Endocrinology and Diabetology, Medical University of Graz, Austria), for critical review and editorial assistance with the article. J.R.H. was funded by the Austrian Science Fund (FWF) through the $\mathrm{PhD}$ program Molecular Fundamentals of Inflammation (DK-MOLIN, W1241) and the BOSCH-Forschungsstiftung (Essen, Germany). This study was sponsored, in part, by Animas Corporation (a Johnson \& Johnson Company) and Thomas Jefferson University, Philadelphia, PA.

\section{Author Disclosure Statement}

J.J. is a co-founder of Animas Corporation (a Johnson \& Johnson Company) where he owned equity and royalties up until 36 months before submission of this article. He is founder of Capillary Biomedical, Inc.; equity owner and advisory board chairman of Capillary Biomedical, Inc. This study was partially sponsored by Animas Corporation.

\section{References}

1. Heinemann L: Insulin infusion sets: a critical reappraisal. Diabetes Technol Ther 2016;18:327-333.

2. Golden SH, Sapir T: Methods for insulin delivery and glucose monitoring in diabetes: summary of a comparative effectiveness review. J Manag Care Pharm 2012;18: $1-20$.

3. Lenhard MJ, Reeves GD: Continuous subcutaneous insulin infusion. Arch Intern Med 2001;161:2293-2300.

4. Schaeffer NE: Human factors research applied: the development of a personal touch screen insulin pump and users' perceptions of actual use. Diabetes Technol Ther 2013;15: 845-854.

5. Heinemann L, Krinelke L: Insulin infusion set: the Achilles heel of continuous subcutaneous insulin infusion. J Diabetes Sci Technol 2012;6:954-964.

6. Schmid V, Hohberg C, Borchert M, et al.: Pilot study for assessment of optimal frequency for changing catheters in insulin pump therapy-trouble starts on day 3. J Diabetes Sci Technol 2010;4:976-982.

7. Deiss D, Adolfsson P, Alkemade-van Zomeren M, et al.: Insulin infusion set use: European perspectives and recommendations. Diabetes Technol Ther 2016;18:517-524.

8. Shetty G, Wolpert H: Insulin pump use in adults with type 1 diabetes-practical issues. Diabetes Technol Ther 2010;12 Suppl 1:S11-S16.

9. Pfützner A, Sachsenheimer D, Grenningloh M, et al.: Using insulin infusion sets in CSII for longer than the recommended usage time leads to a high risk for adverse events: results from a prospective randomized crossover study. J Diabetes Sci Technol 2015;9:1292-1298.

10. Kobayashi T, Sawano S, Itoh T, et al.: The pharmacokinetics of insulin after continuous subcutaneous infusion or bolus subcutaneous injection in diabetic patients. Diabetes 1983;32:331-336.

11. Heinemann L: Variability of insulin absorption and insulin action. Diabetes Technol Ther 2002;4:673-682.

12. Yang YJ, Hope ID, Ader M, Bergman RN: Insulin transport across capillaries is rate limiting for insulin action in dogs. J Clin Invest 1989;84:1620-1628.

13. Binder $\mathrm{C}$, Lauritzen $\mathrm{T}$, Faber $\mathrm{O}$, Pramming $\mathrm{S}$ : Insulin pharmacokinetics. Diabetes Care 1984;7:188-199.

14. Anderson JM, Rodriguez A, Chang DT: Foreign body reaction to biomaterials. Semin Immunol 2008;20:86-100. 
15. Gifford R, et al.: Protein interactions with subcutaneously implanted biosensors. Biomaterials 2006;27:2587-2598.

16. Bryers JD, Giachelli CM, Ratner BD: Engineering biomaterials to integrate and heal: the biocompatibility paradigm shifts. Biotechnol Bioeng 2012;109:1898-1911.

17. Matlaga BF, Yasenchak LP, Salthouse TN: Tissue response to implanted polymers: the significance of sample shape. J Biomed Mater Res 1976;10:391-397.

18. Pickup JC, Yemane N, Brackenridge A, Pender S: Nonmetabolic complications of continuous subcutaneous insulin infusion: a patient survey. Diabetes Technol Ther 2014; 16:145-149.

19. Patel PJ, et al. Randomized trial of infusion set function: steel versus teflon. Diabetes Technol Ther 2013;16:1-5.

20. Zhang Y, Huo M, Zhou J, Xie S: PKSolver: an add-in program for pharmacokinetic and pharmacodynamic data analysis in Microsoft Excel. Comput Methods Programs Biomed 2010;99:306-314.

21. Rolls GO: Difficult blocks and reprocessing. 2011. www .leica-microsystems.com/fileadmin/academy/2011/95.9890_ Rev_A_Difficult_Blocks.pdf (accessed June 1, 2016).

22. Plum A, Agerso H, Andersen L: Pharmacokinetics of the rapid-acting insulin analog, insulin aspart, in rats, dogs, and pigs, and pharmacodynamics of insulin aspart in pigs. Drug Metab Dispos 2000;28:155-160.

23. Vlasakakis G, Johnson SL, Lin J, et al.: Pharmacokinetics and tolerability of exenatide delivered by 7-day continuous subcutaneous infusion in healthy volunteers. Adv Ther 2015; 32:650-661.

24. Karlin AW, Ly TT, Pyle L, et al.: Duration of infusion set survival in lipohypertrophy versus nonlipohypertrophied tissue in patients with type 1 diabetes. Diabetes Technol Ther 2016;18:429-435.

25. Salthouse TN: Some aspects of macrophage behavior at the implant interface. J Biomed Mater Res 1984;18:395-401.

26. Meyer W, Schwarz R, Neurand K: The skin of domestic mammals as a model for the human skin, with special reference to the domestic pig. Curr Probl Dermatol 1978; 7:39-52.

27. Wang JF, Olson ME, Reno CR, et al.: The pig as a model for excisional skin wound healing: characterization of the molecular and cellular biology, and bacteriology of the healing process. Comp Med 2001;51:341-348.

28. Seaton M, Hocking A, Gibran NS: Porcine models of cutaneous wound healing. ILAR J 2015;56:127-138.

29. Sullivan TP, Eaglstein WH, Davis SC, Mertz P: The pig as a model for human wound healing. Wound Repair Regen 2001;9:66-76.
30. Thomsen M, Hernandez-Garcia A, Mathiesen J, et al.: Model study of the pressure build-up during subcutaneous injection. PLoS One 2014;9:e104054.

31. Pickup JC, Sherwin RS, Tamborlane WV, et al.: Conference on insulin pump therapy in diabetes. Multicenter study of effect on microvascular disease. The pump life. Patient responses and clinical and technological problems. Diabetes 1985;34 Suppl 3:37-41.

32. Ruan Y, Wilinska ME, Thabit H, Hovorka R: Modeling day-to-day variability of glucose-insulin regulation over 12-week home use of closed-loop insulin delivery. IEEE Trans Biomed Eng 2017;64:1412-1419.

33. Conwell LS, Pope E, Artiles AM, et al.: Dermatological complications of continuous subcutaneous insulin infusion in children and adolescents. J Pediatr 2008;152:622-628.

34. Hojbjerre L, Skov-Jensen C, Kaastrup P, et al.: Effect of insulin catheter wear-time on subcutaneous adipose tissue blood flow and insulin absorption in humans. Diabetes Technol Ther 2009;11:575-580.

35. Bergman RN: Insulin action and distribution of tissue blood flow. J Clin Endocrinol Metab 2003;88:4556-4558.

36. Groth L, Serup J: Cutaneous microdialysis in man: effects of needle insertion trauma and anaesthesia on skin perfusion, erythema and skin thickness. Acta Derm Venerol 1998; 78:5-9.

37. Swan KL, Dziura JD, Steil GM, et al.: Effect of age of infusion site and type of rapid-acting analog on pharmacodynamic parameters of insulin boluses in youth with type 1 diabetes receiving insulin pump therapy. Diabetes Care 2009;32:240-244.

38. Clausen TS, Kaastrup P, Stallknecht B: Effect of insulin catheter wear-time on subcutaneous adipose tissue blood flow and insulin absorption in humans. Diabetes Technol Ther 2009; 11:575-580.

Address correspondence to: Jeffrey I Joseph, DO Department of Anesthesiology Jefferson Artificial Pancreas Center Sidney Kimmel Medical College Thomas Jefferson University Jefferson Alumni Hall, Suite \#565 1020 Locust Street Philadelphia, PA 19107

E-mail: jeffrey.joseph@jefferson.edu 